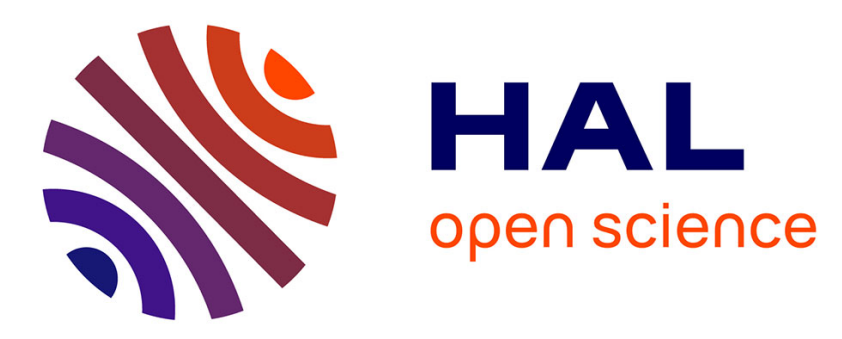

\title{
How Additive Manufacturing Improves Product Lifecycle Management and Supply Chain Management in the Aviation Sector?
}

Alejandro Romero, Darli Rodrigues Vieira

\section{To cite this version:}

Alejandro Romero, Darli Rodrigues Vieira. How Additive Manufacturing Improves Product Lifecycle Management and Supply Chain Management in the Aviation Sector?. 12th IFIP International Conference on Product Lifecycle Management (PLM), Oct 2015, Doha, Qatar. pp.74-85, 10.1007/9783-319-33111-9_8. hal-01377430

\author{
HAL Id: hal-01377430 \\ https://hal.inria.fr/hal-01377430
}

Submitted on 7 Oct 2016

HAL is a multi-disciplinary open access archive for the deposit and dissemination of scientific research documents, whether they are published or not. The documents may come from teaching and research institutions in France or abroad, or from public or private research centers.
L'archive ouverte pluridisciplinaire HAL, est destinée au dépôt et à la diffusion de documents scientifiques de niveau recherche, publiés ou non, émanant des établissements d'enseignement et de recherche français ou étrangers, des laboratoires publics ou privés.

\section{(c)(1)}

Distributed under a Creative Commons Attribution| 4.0 International License 


\title{
How additive manufacturing improves product lifecycle management and supply chain manage- ment in the aviation sector?
}

\author{
Alejandro Romero ${ }^{1}$ and Darli Rodrigues Vieira ${ }^{2}$ \\ ${ }^{1}$ School of management (ESG), Université du Québec à Montréal (UQAM), Research \\ Chair in Management of Aeronautical projects (UQTR) and Chair in Project Management \\ (ESG UQAM), Canada; romero-torres.alejandro@uqam.ca, \\ ${ }^{2}$ Université du Québec à Trois-Rivières (UQTR) and Research Chair in Management of \\ Aeronautical projects (UQTR), Canada; darli.vieira@uqtr.ca
}

\begin{abstract}
Aviation is a high competitive industry where actors should be first adopters for leading market or following adopters to survive. Traditional manufacturing techniques pass into the background, manufacturing systems require using additive technologies for rapid adaptation to current demand and reduction of production cycle duration. Many large mechanic and aircraft engineering companies have already adopted additive manufacturing technologies in their future production strategy. The general concept of 3D printer on the basis of emanufacturing principles is aimed at integration of computer models of physical objects and processes. This change requires a deep transformation into enterprise business model, affecting either core or support activities. For instance, additive manufacturing could also change product lifecycle and supply chain management practices. This paper aims to identifying how these new technologies could improve support activities for aeronautical industry? Results show that additive manufacturing triggers a paradigm shift for aircraft lifecycle management and enable lean and agile practices for supply chain management.
\end{abstract}

Keywords: additive manufacturing, product lifecycle management, supply chain management, agile, $3 \mathrm{D}$ printing

\section{Introduction}

Aviation is a high competitive industry where actors should be first adopters for leading market or following adopters to survive. With a decreasing market size, aviation manufacturers are competing more than ever to gain new contracts. Customer, such as airlines, private and public organizations or civilian, are looking to spend less money and get the best products possible (Franke and John, 2011). These factors create an enormous challenge for aviation actors to manufacture products with high performance, short production cycle time, low cost and fierce competition (Witick et al., 2012). Within technology evolution, major manufacturing firms invest hundreds of millions of dollars in introducing new innovations to improve their products or services to overtake their competitors.

Additive manufacturing AM seems to be the next hype technology driver for aviation industry to improve manufacturing operations (Smartech Markets, 2014). AM, commonly known as $3 \mathrm{D}$ printing, could be adopted to manage aircraft production, characterized by low manufacturing volumes, personalization, complex geometries and optimal balance between mechanical resistance of parts and weight (Hopkinson et al., 2006). McKinsey Global Institute (2013) estimates AM will generate up to 550,000 million of savings annually in 2025. 
AM is considered as the real cornerstone of the industrial future for the most developed countries (Gebhardt, 2012). AM is often presented as an industrial revolution, based on innovative technologies, challenging traditional manufacturing models and upsetting the relationship between actors (Hopkinson et al., 2006). However, this transformation cannot be reduced to the production activities, it could also require operational optimization for the entire enterprise business model, including support functions such as supply chain management or product lifecycle management. This paper aims to provide information about this transformation.

The objective of this paper is to assess how AM could transform product lifecycle management PLM and supply chain management SCM practices for aviation operations. In the following section, we first discuss the employment of AM and the trends in manufacturing. We then outline the basic features of aviation sector and its AM applications. In the next section, we describe key transformations for PLM and SCM practices. Finally, in the concluding section we state some implications of our study as well as directions for future research.

\section{Additive Manufacturing}

\subsection{The third industrial revolution}

In the last three decades, industries have experienced a transition to digital. This evolution can be illustrated by technological changes, such as: offices have moved from paper hand drawn design planes to parametric files, first in two dimensions (2D computer-aided-design software $\mathrm{CAD}$ ) and then in three dimensions (3D CAD); communications have move from sending postal mail to the first appearance of the fax and then email. Manufacturers are not immune to this phenomenon. Traditional manufacturing techniques passes into the background, manufacturing systems require using of additive technologies for rapid adaptation to current demand and reduction of production cycle duration (Fogliatto, 2010). Indeed, several researchers consider this transition as the third industrial revolution (Berman, 2012; Rifkin, 2012).

Digital capabilities allow high speed processing of data overcoming unknown limits such as reliability and accuracy. For manufacturing industries, digital technologies could improve operation by introducing data and control technologies such as computer-aided-design (CAD), computer-aided-manufacturing (CAM) or computer-aided-engineering (CAE). However, manufacturing processes remain basically the same: first digital design, then piece production by material removal, cold or heat forming, casting or injection, and finally, surface finishing (Tiwary and Harding, 2011). The above processes face several limits such as high cost of tooling and machinery for complex geometries, long and complex supply chain to lower tooling costs (Berman, 2013), high "time to market" for new designs, loss of flexibility in decisionmaking due to tooling cost and development time (Gebhardt, 2012); tooling collisions when complex geometries, curved cutting edges and drafting angle constraints, design and manufacturing tools designed to use Design for Manufacture and Assembly (DFMA) generating constraints for product design and, although not necessary for geometries, use of solid pieces (Grimm, 2004).

Furthermore, this manufacturing model is based on mass production (Fogliatto, 2010). Standardized parts and processes made economies of scale achievable, but limited design flexibility and personification. These limitations could block manufacturers' creativity and constitute a barrier for developing new products with high added value or new functionalities (Fogliatto, 2010).

E-manufacturing or "smart production", the use of advanced and emerging information 
technologies to provide automated data-driven productivity optimization, takes advantage of all knowledge developed in the digital age to overcome the above traditional manufacturing limitations (Nyanga et al., 2012). At the heart of this new industrial revolution is additive manufacturing AM, which enables manufacturing complex geometries for several industries such as aviation, aerospace industry, power and healthcare.

\subsection{Additive manufacturing definition}

$\mathrm{AM}$, more commonly known as 3D printing, is a process of creating a three dimensional object or 3D-model from a digital model. Using an AM machine, or printer, successive layers of material are very precisely laid down in arranged patterns and lines in accordance with the digital design. Wohlers and Caffrey (2013) defined AM as the direct manufacturing of finished products with additives construction processes through a bottom-to-top approach by combining materials without any traditional tool or equipment. AM is used to produce models, prototypes, patterns, components, and parts using a variety of materials including plastic, metal, ceramics, glass, and composites (Lyons, 2014).

In traditional manufacturing processes, a complex geometry requires more sophisticated manufacturing process, which results in an additional cost (Gibson et al., 2010). For AM, an elaborated geometry doesn't generate complexity for the manufacturing process; it enables material savings and time reductions. In addition, some complex items require joining several pieces to form the final product (Campbell et al., 2011). These elements are separately manufactured and they are integrating at the end of the manufacturing process. Fortunately, AM allows manufacturing these complex items in a single process enabling integration during design process (Wohlers and Caffrey, 2013).

\subsection{Additive manufacturing processes}

Although the variety of different additive manufacturing techniques, they all follow the same pattern. As shown in the figure 1, AM processes could be divided into three fixed phases, namely digital phase, manufacturing phase and post-process phase.

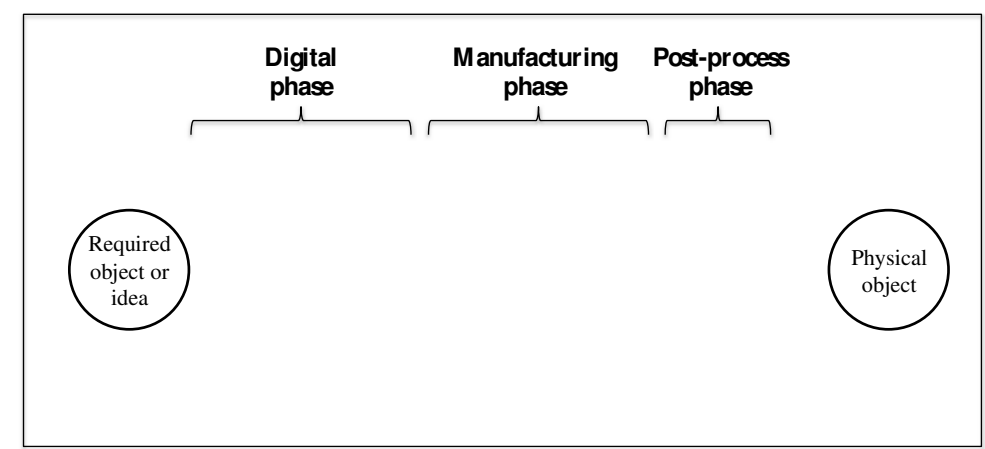

Figure 1. Additive manufacturing processes

Digital phase: This phase included two main activities:

- Computer-aided design CAD: Object design is performed to get its digital design in 3D (Grimm, 2004). CAD takes a series of digital images of a design or object and sends descriptions of them to an AM industrial machine. 3D design enables improving quality and reducing overall developmental time and costs by creating a model that is precise, easily replicated, and easily conceptualized (Schindler, 2010).

- Standard Tessellation Language STL: CAD software generates process files for AM ma- 
chine in STL format. These files should be verified to avoid errors that may affect the total quality of the end product (Grimm, 2004). Errors are identified and corrected by STL repair program or returning the file back to the design stage.

Manufacturing phase: This phase included two main activities:

- Machine setup: STL files are transferred to the AM machine and raw materials for object production are loaded.

- Production part: It is the process in which the AM machine uses the STL files to create the item by adding material layer-upon-layer. Layers, which are measured in microns, are added until a three-dimensional object emerges. AM machines could operate 24 hours a day without human intervention (Campbell et al., 2011). The only labour involved is the machine setup, build launch, and the removal of the prototypes or object upon completion. This phase can be directly last if the part does not require a withdrawal of supports or better than that offered by the machine surface finish (Schindler, 2010).

Post-process phase: The part is then removed from the AM machine for post-processing such as removal of sacrificial supports for any overhanging edges. Cleaning and finishing of the object is the most manual, labour-intensive portion of the AM process (Grimm, 2004). Sometimes, object should go though other manufacturing procedures such as thermal operations or copper empty for improving its properties.

\subsection{Additive manufacturing applications}

$\mathrm{AM}$ is industrially used for three main types of application: for developing prototypes known as rapid prototyping, for manufacturing tooling known as rapid tooling and for manufacturing functional mechanical parts known as direct manufacturing or rapid manufacturing.

- Rapid prototyping is the main application for AM (Bibb et al., 2015). Prototypes require no dedicated tools and are produced in small series, generating high costs for industries. $\mathrm{AM}$ enables developing in short time prototypes with relatively low costs and using different type of materials. Furthermore, a rapid prototype can be used either for visual or functionality validation for final product reducing its development time.

- Rapid tooling provides a significant increase in speed and reduction in cost for complex tools (Campbell et al., 2011). This application allows replacing conventional steel tooling by soft material such as epoxy-based composites with aluminum particles, silicone rubber or low-melting-point alloys (Noble et al., 2014).

- Direct manufacturing is the latest application developed using AM processes. It accounts a very small part of the market (Wohlers and Caffrey, 2012). It used for lowvolume products for aerospace, automotive or medical sector. However, direct manufacturing will also have implications for medium- to high-volume production as the AM technologies improve (Hague et al., 2003).

\subsection{Additive manufacturing benefits}

Berman (2012) drew an analogy between AM effects and those observed during the emergence of digital printing 20 years ago. Digital printing has completely transformed the industry in a few years, since business change their model business to integrate digital competencies. Based on $2 \mathrm{D}$ printing effects, we can anticipate what will happen with $\mathrm{AM}$ in the world of manufacturing:

- Design benefits: AM technologies bring creativity and flexibility for product design. AM machines can produce parts with almost any shape or complexity and without geometric limitations as the conventional manufacturing processes. In traditional manufacturing processes, there is a direct connection between complexity and manufacturing costs (Wohlers and Caffrey, 2012). A relationship tying cost to complexity does not exist in 
AM. Furthermore AM technologies permits to manufacture objects with any shape or branching for circulation channels or with internal cavities (Campbell et al., 2011).

- Manufacturing benefits: AM does not require any type of tooling as conventional manufacturing processes. From this feature, two advantages could be identified. First, investment in tooling for manufacturing parts is not necessary (Lyons, 2014). Second, there are no manufacturing geometric constraints arising from the use of tools, such as collision of pieces during machining or draft angles during part injection (Lyons, 2014). In addition, AM enables tools or pieces with $100 \%$ density (in the case of metal technology). These objects have no residual porosity generating excellent mechanical properties, unlike conventional powder metallurgical processes (Hopekinson, 2006).

- Material benefits: AM permits maximum saving of material. The material is selectively added and not subtracted from a block. For some applications, wastes produced from raw material, especially in the metal sector, are reduced up to $40 \%$ when additive manufacturing technologies are used instead of subtractive technologies (machining). Thomas and co authors (2014) showed AM permits to reduce objects weight by $21 \%$. In addition, between $95 \%$ and $98 \%$ of the material used can be totally recycled (Reeves et al., 2011).

- Time benefits: AM enables reducing the time required for placing on the market custom products (time-to-market). The introduction of new products is less risky than before, due to the elimination of costly production tooling and to the development of prototypes (Hopekinson, 2006). This has a strong impact on the post-processing of existing products. Changes in the design can be published to the market even faster. Thomas and co authors (2014) studied AM impact on small innovative enterprises and they showed that organizations could save 24 days in production time.

AM has a low production speed, therefore, it's not used for large production volumes. Therefore, AM should be used considering where its application is an advantage and not for integral manufacturing (Reeves et al., 2011). In the last case, AM may be complement with traditional manufacturing processes.

\section{Additive manufacturing in the aviation sector}

Many large mechanic and aircraft engineering companies have incorporated or are incorporating these technologies in their daily operations. AM is manly used for military and civil applications, accounting for approximately $12.1 \%$ of AM investment in U.S.A (Ford, 2014). For instance, Boeing uses 3D printings to produce 200 pieces that are installed into 10 different aircrafts (Harris and Director, 2011). A F-18 aircraft contains more than 90 3D-printedcomponents such as air ducts and light pieces (Gibson et al., 2010). As well, Boeing has included 32 different components for its 787 Dreamliner planes (Freedman, 2012).

AM holds significant potential for driving down costs in the aviation sector by enabling manufacturing objects which are lightweight, strong, and geometrically complex and typically produced in small quantities (Smelov, 2014). Given that aviation products are mainly manufactured using expensive raw materials such as titanium, plastic, and other lightweight materials, AM could decrease production cost by keeping material amount used to a minimum. For instance, Airbus is assessing 90 separate cases where AM could be adopted to produce tools and pieces with less raw materials (10\% less compared to the traditional manufacturing) (Wood, 2009). In addition, Airbus is developing prototypes to manufacture most of its aircraft parts from ducts to turbine blades with AM technologies (Gebhardt, 2012).

Cost economies could also be observed for complex geometries. Manufacturing cost increases within pieces' complexity for conventional methods. In contrast for AM technologies, there is not related complexity cost, resulting in a low cost strategy with higher added value. 
For instance, Turbomeca is employing AM technologies to manufacturing fuel injectors and combustion chamber turbines for helicopter engines, resulting in cost economies.

AM is also a driver to build a greener aircraft by reducing components' weight. A reduction of one kilogram in the weight of an aircraft could reduces carbon emissions and save $\$ 3,000$ US in fuel per year (Ford, 2014). For instance, GE is manufacturing $20 \%$ of its turbojet components for commercial aircraft using AM. These components are $25 \%$ lighter and as much as five times more durable than the existing model (Zaleski, 2015). GE has also announced a \$50-million investment to implement AM infrastructure for its factory in Alabama (Zaleski, 2015). As GE, Pratt and Whitney has produced more than a dozen pieces of its PW1500G engine which is used in the new Bombardier C-Series aircraft.

Aviation manufacturers and service providers could get advantage from AM technologies to reduce their lead-time for either new or replacement parts. Smartech Markets (2014) stated that lead-time for a part could by reduced by $80 \%$, compared with conventional manufacturing methods." For instance, Kelly Manufacturing Company, the world's largest manufacturer of general aviation instruments, has reduced their production time "for 500 housing components from three-to-four weeks to just three days using AM technologies" (Smartech Market 2014).

\section{Additive manufacturing impacts for PLM and SCM}

Many large manufacturers and system providers state that aircrafts configuration frequently changed, generating complexity for PLM and SCM. In particular, complexity could vary in function of customer's requirements or internal factors that leads to a delayed delivery or over budget. Furthermore, aviation organizations operate in a highly reactive environment not favourable to supporting strategic planning. Thus, these companies sometimes fail to improve product, its lifecycle and its supply chain.

\subsection{PLM and AM}

PLM, much more than a technology solution, is a strategy that contributes to share product data within the organization and throughout its value chain. PLM goal is to effectively and efficiently innovate, manage products and their related services from upstream to downstream of their lifecycle (see topside figure 2), and finally, optimize production processes. PLM also facilitates the continuous involvement and communication of internal and external stakeholders. Aviation industry, investing in PLM, seeks for mastering the full aircraft lifecycle, improving information and decision traceability, facilitating information communication among stakeholders and developing an optimal process flow.

AM could strengthen PLM competencies by enabling advances to improve aircraft performance, such as innovation capacity, frequency and time to market, quality assurance and development costs and materials control. As showed in the figure 2, AM could be used for rapid prototyping, rapid manufacturing and rapid tooling:

- Rapid prototyping enables to improve mainly two aircraft lifecycle phases, namely prefeasibility/feasibility and design. In this case, AM accelerates product development cycles from its design. In addition, 3D printers could be a wave for accelerating time to market as prototypes can be launched in short time to assess its performance or customer's satisfaction.

- Rapid manufacturing could be adopted for three main phases: part and system production, assembly and maintenance, repairing and overhaul MRO. AM has the potential to reduce the costs of storing, moving, and distributing raw materials, mid-process parts, and end-usable parts. The ability to produce parts on demand without the need 
for tooling and setup could decrease production and MRO cycle times, as well as their related cost.

- Rapid tooling could be implemented for three phases, namely aircraft assembly, MRO and final disposal AM enables building tools when they are required. This could bring several benefits for MRO and final disposal where service suppliers should manage several types of aircrafts requiring different type of tools for disassembling, repairing and assembling aircraft systems, parts or pieces.

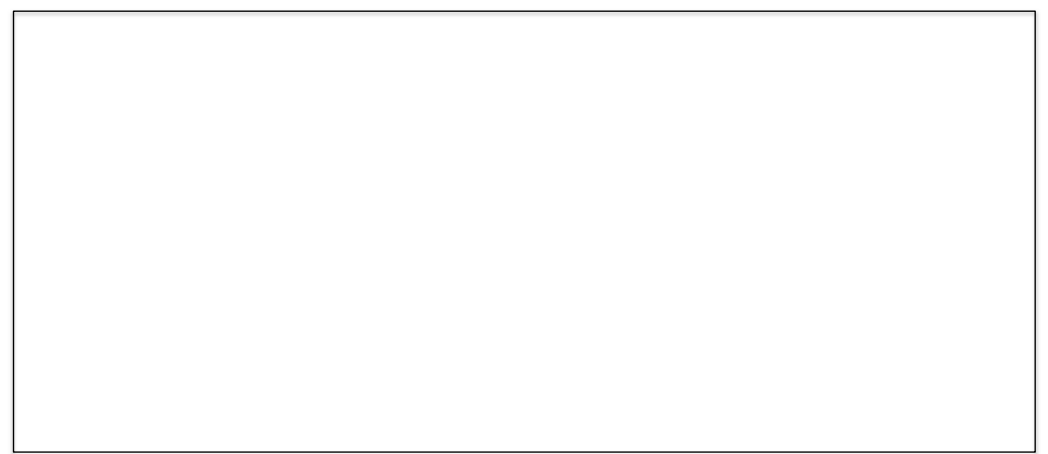

Figure 2. Aircraft product lifecycle and AM applications

AM changes deeply PLM paradigm since aviation organizations could focus on designing products with higher performance or functionality and without considering assembly or manufactory constraints. Design for Assembly and Design for Manufacturing methodologies aim to making products easier to manufacture and assembly based on the characteristics of current manufacturing methods, however these characteristics no longer apply when taking into account AM capabilities. Furthermore, piece design is improved with AM since aviation professionals can exchange their vision for the proposed solution into an easy common and visual language, accelerating analysis time and decision making. A design paradigm shift is needed in order to "bring designers and manufacturers to stop thinking in terms of limitations, but to think in terms of possibilities" (Rosenberg, 2008).

Finally, aircraft product cycles are characterized by long periods of time for technology maturity (between 10 to 20 years), for aircraft development (between 5 to 7 years), for aircraft production (between 15 to 20 months) and for MRO aircraft (between 2 days to 2 months). For commercial planes whose average life expectancy is almost 30 to 40 years, circumventing the need to maintain and replace old tooling is a notable inventory cost advantage for manufacturers. Airbus believes that AM holds the potential to keep the turnaround for test or replacement parts as low as two weeks. These parts can be rapidly shipped to and installed in a broken down plane to help get the plane back into the air and making money for the airline.

\subsection{SCM and AM}

Constructors and services providers execute aircraft production and its maintenance into extend supply chain frames, which result in increasing costs. Aviation industry must manage different providers (see figure 3), different aircraft pieces and deal with the variability of pieces and nomenclature. For example, an Airbus A380 requires more than 100,000 wires (Romero et Rodrigues, 2013). Finally, with the pressure to increase production pace, organizations should have the capacity to identify needs more quickly based on the establishment of a collaborative relationship with its suppliers (ranks 1 and 2) and its customers. 


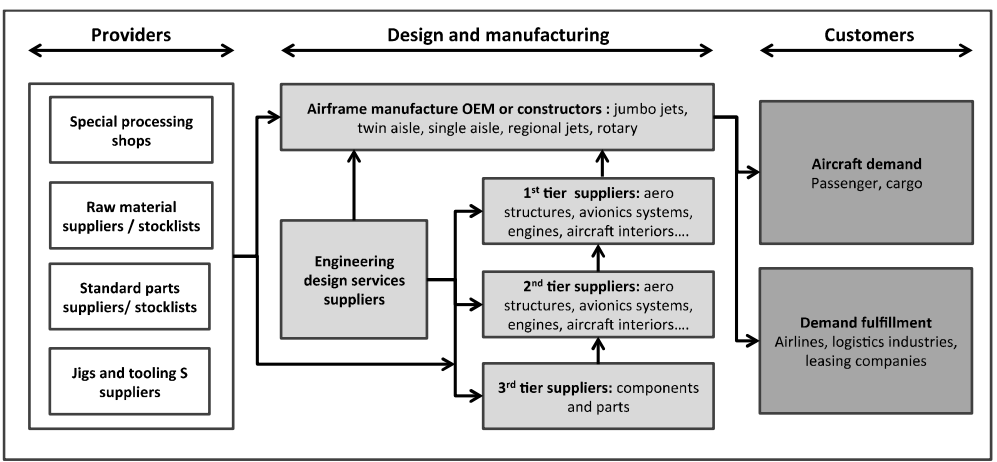

Figure 3. Aircraft development and production actors (adapted from Autodesk, 2009)

AM could support SCM competencies by decreasing supply chain complexity. AM applications made supply chains more elastic, bringing manufacturing closer to the assembly, utilisation and MRO location. Following this approach, there will be fewer requirements for part and components transportation, which alter the production and MRO flow and will almost disappear logistics costs. AM enables industrial relocation with important issues such as production deregionalization for pieces, economies for import and export customs and environmental footprint reduction. Indeed, an aircraft integrator would not need to bring all the pieces from remote countries (such as Airbus which transports aircraft pieces from Spain, Germany, Portugal and England to France); they can be manufactured on-site (in Toulouse, France).

AM enables production and MRO without stock, which implies a supply chain more efficiently and less risky (Khajavi et al., 2014). For instance, MRO providers could have minimum inventory level for each piece since they could manufacture them if required, thus this enables reducing the need of maintaining safety inventory. In this case, organizations don't need to keep in stock high cost and long-lead parts such gear rotors because they can print them when needed. Therefore, management of spare parts inventory should require reorganization. Aircraft spare parts demand pattern follows a 20/80 Pareto curve: $80 \%$ of the parts are needed frequently; but they only account for $20 \%$ of the supply chain expenditure (Liu et al., 2014). In this case, two different approaches to integrate AM technologies could be adopted, namely centralized and distributed supply chain (Holmstrom et al., 2010). The centralized is more suitable for parts with low average demand; relatively high demand fluctuation and longer manufacturing lead-time ( $20 \%$ of the parts needed). The distributed one is suitable for parts with high average demand or very stable demand and short manufacturing lead-time ( $80 \%$ of the parts demanded).

AM applications could also trigger lean and agile practices in the aviation supply chain. $\mathrm{AM}$ enables a greater production flexibility, which is achieved by reduction of time of new production launching and inventory, efficient capacity utilization, which is provided through labour costs reduction, delivery of materials calculation depending on the needs, special arrangement of production facilities.

\section{Conclusions}

Is AM a new industrial revolution? This paper has showed that aviation organizations are rethinking their business model by adopting AM technologies. AM changes PLM and SCM paradigm by eliminating manufacturing and assembling limits, by improving product design and by reducing lead-time for aircraft development, production and MRO. Therefore, aviation industry could become more agile and "lean". AM enables the elimination of waste in tooling, 
materials, labour and methods of production and reducing time to improve efficiency throughout the aviation supply chain and aircraft lifecycle.

Although the above improvements, there are limitations that make AM technologies have not yet been widely adopted in the aviation sector. The current drawbacks are slow print speed limiting AM use for mass production, technology costs, material quality problems and reliability and reproducibility limits. Furthermore, SCM and PLM aviation actors should integrate all together AM capacities to support 3D manufacturing flow. The AM process is well known, but now they should overcome some manufacturing constraints and explore new forms for 3D design. Such limitations are certainly surmountable, and constitute challenges for research, technological development and innovation.

New research issues emerge through our study. We have outlined how AM remodels PLM and SCM for aviation sector. Important issues rise when an innovation is adopted by an organization triggering important changes into core competencies. How should aviation organizations manage this transformation? Are environmental, technology or organization factors affecting AM adoption? Finally, from a marketing perspective, effective ways to demonstrate AM impacts should be studied, in order to gain maximum support from aviation actors.

\section{References}

Autodesk, 2009. Digital prototyping for the Aerospace Supply Chain, white paper.

Berman, B., 2012. 3-D printing: The new industrial revolution. Business horizons, 55(2), 155-162.

Bibb, R., Bocca, A., Sugar, A., Evans, P. (2015). Surgical applications. Medical Modelling: The Application of Advanced Design and Rapid Prototyping Techniques in Medicine, 137.

Campbell, R.I., De Beer, D.J., Pei, E., 2011. Additive manufacturing in South Africa: building on the foundations. Rapid Prototyping Journal, 17(2), 156-162.

Fogliatto, F., 2010. Mass Customization: Engineering and Managing Global Operations. Springer.

Ford, S.L., 2014. Additive Manufacturing Technology: Potential Implications for US Manufacturing Competitiveness. Journal of International Commerce and Economics, 1-35.

Franke, M., John, F. (2011). What comes next after recession?-Airline industry scenarios and potential end games. Journal of Air Transport Management, 17(1), 19-26.

Freedman, D.H., 2012. Layer by layer. Technology Review, 115(1), 50-53.

Gebhardt, A., 2012. Understanding Additive Manufacturing: Rapid Prototyping, Rapid Tooling, Rapid Manufacturing. Hanser Gardner Publications.

Gibson, I., Rosen, D.W., Stucker, B., 2010. Additive manufacturing technologies. Rapid prototyping to direct digital manufacturing. New York ; London: Springer.

Grimm, T. (2004). Users' guide to rapid prototyping. Dearborn, MI: Society of Manufacturing Engineers.

Hague, R., Campbell, I., Dickens, P., 2003. Implications on design of rapid manufacturing. Journal of Mechanical Engineering Science, 217(1), 25-30.

Harris, I.D., Director, A.M.C., 2011. Development and Implementation of Metals Additive Manufacturing. DOT International, New Orleans.

Holmstrom, J., Partanen, J., Tuomi, J., Walter, M., 2010. Rapid manufacturing in the spare parts supply chain: alternative approaches to capacity deployment, Journal of Manufacturing Technology Management 21(6), 687-697.

Hopkinson, N., Hague, R.J.M., Dickens, P.M., 2006. Rapid manufacturing. An industrial revolution for the digital age. Chichester England, John Wiley.

Khajavi, H., Partanen, J., Holmstrom, J., 2014. Additive manufacturing in the spare parts supply chain. Computers in industry, 65, 50-63.

Liu P., Huang S.H., Mokasdar A., Zhou H., Hou L., 2014. The impact of additive manufac- 
turing in the aircraft spare parts supply chain: supply chain operation reference (SCOR) model based analysis, Production Planning \& Control: The Management of Operations, 25(13-14), 1169-1181.

Lyons, B., 2014. Additive manufacturing in aerospace: Examples and research outlook. The Bridge, 44(3), 13-19.

McKinsey, 2013. Industrie 2.0, Jouer la rupture pour une Renaissance de l'industrie française. Consulted from : http://www.innovation.rhone-alpes.cci.fr/

Noble, J., Walczak, K., Dornfeld, D., 2014. Rapid Tooling Injection Molded Prototypes: A Case Study in Artificial Photosynthesis Technology. Procedia CIRP, 14, 251-256.

Nyanga, L., Van Der Merwe, A.F., Matope, S., Tlale, N., 2012. E-Manufacturing: A Framework For Increasing Manufacturing Resource Utilisation. CIE42 Proceedings, 16-18.

Reeves, P., Tuck, C., Hague, R., 2011. Additive manufacturing for mass customization. In Mass Customization. Springer London, 275-289.

Rifkin, J., 2012. The third industrial revolution: How the internet, green electricity, and 3-d printing are ushering in a sustainable era of distributed capitalism. World Financial Review, 1.

Romero, A. Rodrigues, D., 2013. Traceability as a key competency for the aeronautical industry : an exploratory study. International Journal of Business and Management Studies, 2(2), 443-457.

Schindler, C., 2010. Product life cycle management: A collaborative tool for defense acquisitions (Master's thesis). Monterey CA: Naval Postgraduate School.

Smartech Markets, 2014. Additive manufacturing in aerospace: Strategic implications. White paper. Consulted from : http://www.smartechpublishing.com

Smelov, V.G., Kokareva, V.V., Malykhin, A.N., 2014. Lean Organization Of Additive Manufacturing Of Aircraft Purpose Products. International Journal of Engineering \& Technology, 6(5).

Thomas, D.S., Gilbert, S.W., 2014. Costs and Cost Effectiveness of Additive Manufacturing. U.S. Department of Commerce. Consulted from : http://nvlpubs.nist.gov/nistpubs/Special Publications/NIST.SP.11 76.pdf

Tiwari, M., Harding, J.A., 2011. Evolutionary Computing in Advanced Manufacturing. John Wiley \& Sons and Scrivener Publishing.

Witik, R.A., Gaille, F., Teuscher, R., Ringwald, H., Michaud, V., Månson, J.A.E. 2012. Economic and environmental assessment of alternative production methods for composite aircraft components. Journal of Cleaner Production, 29, 91-102.

Wohlers, T., Caffrey, T., 2013. Additive manufacturing: going mainstream. Manufacturing Eng, 151(6), 67-73

Wood, D., 2009. Additive Layer manufacturing at Airbus-Reality check or view into the future?. TCT Magazine, 17(3), 23-27.

Zaleski (2015). GE's bestselling jet engine makes 3-D printing a core component. Fortune. Consulted from : http://fortune.com/2015/03/05/ge-engine-3d-printing/ 